\title{
Optimisation of processing routes for a marine biorefinery
}

Luis T. Antelo ${ }^{1}$, Gundián M. de Hijas-Liste ${ }^{1,2}$, Amaya Franco-Uría ${ }^{2 *}$, Antonio A. Alonso ${ }^{1}$ and R. I. Pérez-Martín ${ }^{1}$

${ }^{I}$ Process Engineering Group, Marine Research Institute IIM-CSIC Eduardo Cabello, 6-36208 Vigo, Spain.

${ }^{2}$ Dept. of Chemical Engineering, School of Engineering, University of Santiago de Compostela, 15782 Santiago de Compostela, Spain. 


\section{Abstract}

Current fishing practices result in the waste of 20 million tonnes of valuable resources every year. However, from now on, vessels must keep on board and land both target and those non-target species subject to quota regulations, as regulated by recent EU legislation, in the reform of the Common Fisheries Policy (CFP). Therefore, an important quantity of low-value marine biomass has to be managed in an efficient manner to avoid its waste. Several added value products apart from fishmeal and oil (like enzymes or nutraceuticals) can be obtained from the wide variety of discarded species trough different valorisation processes. The challenge arises when these species can be handled by more than one processing route. The selection of the best alternatives has to fulfil often-opposite sustainability criteria, considering also the constraints associated to each resource and process. This was achieved by a multiobjective framework using a suitable and efficient optimization approach based on scatter-search. The results from the obtained Pareto fronts show that, in general, the valorisation of specific fish parts rather than the use of the whole specimen is more optimal from both points of view. It is also demonstrated that the most suitable products to be obtained are biopeptides, chondroitin sulphate and fish enzymes, due to their high sales price and relative low environmental impact. On the other hand, alternative technologies to present state-of-the-art ones should be considered for the production of chitin, gelatine and fishmeal due to their high environmental cost. Furthermore, a high number of the most optimal valorisation pathways leave biomass unprocessed and therefore, its treatment as solid waste must be included in the economic and environmental costs.

Keywords Fish resources; valorisation processes; environmental and economic criteria; optimal selection. 


\section{Introduction}

Discard practices are the main responsible of the progressive decrease of worldwide extractive catches during the last years (FAO Fisheries and Aquaculture Department. 2012). This non-targeted species represents approximately $20 \mathrm{Mt} /$ year worldwide, 5.2 Mt/year of which are generated in the EU (Kelleher, 2005). Although discards were usually dumped overboard, recently implemented policies, as the new CFP (European Commission, 2013), oblige to unload all the capture in land. Therefore, amounts of this low value biomass are expected to increase in the near future. One of the approaches to face this problem is by the increasing utilization of unavoidable discards/by-catch. Increased by-catch utilisation may come (among others) from a greater demand for fish products, the development of new markets for previously discarded species or the use of low-value by-catch specimens for aquaculture and animal feed. Research on discards utilisation is rapidly moving to the field of food, feeds, nutrition and pharmaceutical research, creating added-value fish products from discarded fish (Blanco et al. 2007; Mahro and Timm 2007; Shahidi 2007; Ferraro et al. 2010; Kim 2012; Freitas et al. 2012; Olsen, et al. 2014; Ordóñez-Del Pazo et al. 2014) . In fact, EC estimates that biotech processes related to these resources have expected growth rates of between $5 \%$ and $10 \%$, which represents a clear opportunity both for R\&D and for business. However, to make the implementation of these new technologies possible, there is a need of selecting the optimal processing routes of the different available biomasses in terms of sustainability. This means that both socioeconomic and environmental objectives must be considered simultaneously.

There is a strong tendency in scientific literature towards the application of different optimization strategies to study the trade-off between these two conflictive objectives. In Gerber et al. (Gerber et al. 2013), master-slave framework combining multi-objective mixed integer linear programming and mixed integer non-linear 
programming was proposed to the environomic design and synthesis of energy systems. Gebreslassie et al. 2013 solve a non-linear programing problem (NLP) for a hydrocarbon biorefinery, considering also economic versus environmental objectives. In this case, the environmental objective was represented by the global warming potential. Greenhouse emissions has also been considered to metric the environmental objective in several examples (Martinez-Hernandez et al. 2013; Murillo-Alvarado et al. 2013), while in other works (Bernardi et al. 2013), the environmental objective was extended by also considering the water footprint.

The optimization of processing routes integrating both criterion was especially applied to the case of biorefineries involving different feedstock types (MartinezHernandez et al. 2013; Murillo-Alvarado et al. 2013; Bernardi et al. 2013; SantibañezAguilar et al., 2014), agave residues (Murillo-Alvarado et al. 2014), jatropha (MartinezHernandez et al. 2014), palm oil (Kasivisvanathan et al. 2012), or algae (GutiérrezArriaga et al. 2014). On the other hand, similar methods could be applied to analyse the trade-off between safety criteria and economics for hydrogen production (El-Halwagi et al. 2013) or the trade-off between net profit and carbon efficiency (Kelloway and Daoutidis 2014).

Among the strategies tested, disjunctive generalized programming (MurilloAlvarado et al. 2013) or fuzzy approaches (Kasivisvanathan et al. 2012; Ng, Hassim, and $\mathrm{Ng} 2013$ ) for sustainable biorefineries design can be mentioned. In most of the cases the associated problem is a non-linear programing problem (NLP) or a mixed integer non-linear programming problem (MINLP), where scatter search (which is a population-based method, eSS) can be successfully applied to solve the associated optimization problem in several chemical and bioprocess problems ( Egea et al. 2007; Egea 2008). Here, this efficient optimization strategy is applied to a marine resource biorefinery to analyse the trade-off between the minimisation of the environmental 
impact and the maximisation of the economic profit. On the other hand, $\varepsilon$-constraint approach (Miettinen 1998; Diwekar 2008) has been the selected method to convert multi-objective problems into a set of single objective problems, due to its easily implementation and capability to obtain uniform distributed Pareto fronts.

Therefore, in this work, we will focus on the necessity of upgrading processes/value chains to make the best possible use of marine biomass and avoid its waste. With that aim, an optimisation screening approach adapted to the particularities of marine biomass discarded in fleets of NW Spain, was developed. Within the framework of the near entrance in force of a more restrictive legislation, the different stakeholders will need basic information on how to manage large quantities of marine biomass every year due to the obligation of landing regulated species nowadays being discarded, creating efficient adding-value chains in land by establishing an efficient valorisation network for that unwanted biomass that we define as the technology model. This multi-layer model links raw material to final products through a set of given technologies.

\section{Case study}

The reason for the selection of this representative case study is that the fishing sector in Galicia (NW Spain) constitutes an important contribution to the total volume of captures in Spain and is considered as one of the largest in the European Union. It must be pointed out that there exists a deep background of tentative, viable solutions/technologies to add value to discarded biomass in the selected area of study (Galicia), in which this work will be put its focus and base its developments (FROM 2009; Alonso et al. 2010; Miguel A. Murado et al. 2010; Ordóñez-Del Pazo et al. 2014), since the fishing sector plays a key role on the socioeconomics dynamics of this region 
representing near to $2 \%$ of the Gross Domestic Product (GDP) and near to $3 \%$ of the total employment.

\subsection{Biomass sources and potential valorisation processes}

In terms of discarded biomass, and as explained in detail (Ordóñez-Del Pazo et al. 2014), the weight distribution between the different species is shown in Table 1. There is a broad discussion in scientific literature (Ferraro et al. 2010; Kim and Mendis 2006; Blanco et al. 2007; Ordóñez-Del Pazo et al. 2014) about pre-industrial scale processes and technologies used to upgrade wastes and discards and to obtain added value products. Fish and fish parts can have a wide range of applications, being the list of possible products (oil, bioactive peptides, chondroitin sulphate, enzymes, gelatine, etc.) as diverse as the industrial sectors that would benefit from the valorisation alternatives. Discards and viscera are good sources for fishmeal, protein hydrolizates, peptones, enzymatic mixtures or fish oil with a high content of unsaturated fatty acids, being these products of interest in sectors such as aquaculture and food. Fishmeal is one of the most common products obtained from fish discards/by-products and has been used as a livestock feed for many years. It is a relatively dry material (Blanco et al. 2007) with a high content in essential amino acids such as lysine, which is often deficient in grain products that are the typical base for most animal feeds (Gildberg 2002). Fish oil consists of a mix of lipids containing different fatty acids, among those two important polyunsaturated fatty acids such as the eicosapentaenoic (EPA) and docosahexaenoic (DHA), and it can be extracted from the whole specimen or from liver (Ferraro et al. 2010). Recent improvements on deodorization and stabilization processes have spread the incorporation of fish oil into food products and beverages for human consumption (Rubio-Rodríguez et al. 2010). 
Surimi and surimi products are obtained from fish muscle, which is the most edible part of the fish (Park 2005). Fish muscle can also be enzymatically hydrolysed to recover bioactive peptides, which have shown many important properties such us antihypertensive, antithomboticm, immunomodulatory and antioxidative activities (S. K. Kim and Mendis 2006; Udenigwe and Aluko 2012). Fish skin or cartilage from some species could be excellent raw materials for products as gelatine or chondroitin sulphate with applications in the food, cosmetic and pharmaceutical sectors (Blanco et al. 2007). In addition, fish internal organs are a rich source of enzymes, for example pepsin, trypsin, chymotrypsin, elastase or collagenase (M.A. Murado et al. 2009; Capasso et al. 1999; Trincone 2011; Arunchalam and Haard 1985; Ascanio et al. 2004). In general, these enzymes present high activity at low concentration and low temperature (Ghaly et al. 2013). They have been used in biotechnology, clinical applications and in diagnosis process (Batista and Pires 2002). Finally, chitin is a marine polysaccharide present in cell walls, exoskeleton of insects and shells of crustacean (Trincone 2011), that presents applications in medicine, pharmacy, food and biotechnology.

\subsection{Proposed valorisation scheme}

Based on the characteristics and properties of the discarded species considered in Table 1, the valorisation scheme showed in Fig. 1 is proposed for the selected metiers. Marine biomass was divided into three main classes, A, B and C. Biomass A covers fish species of small-medium size, biomass B includes crustacean species, and biomass C includes cartilaginous species.

To obtain these products, several valorisation processes or technologies can be used. These processes can use the whole specimen or use only parts of the fish, like liver, cartilage, skin, etc. The technologies considered in this work to valorise the discarded species, as well as the resources consumed in each case are summarized in 
Table 2. In general, these considered valorising processes can be classified in two layers: i) pre-treatment layer $(j=1, . ., 7)$, where the objective is to prepare the raw material to the next processing stage by obtaining adequate intermediate products and ii) final processes $\left(j^{\prime}=1^{\prime}, \ldots, 9^{\prime}\right)$ where the target is to obtain the desired final product. If the whole specimen is used to obtain the final product, then the pre-treatment consists of a grinding process (1). When selected fish parts such as muscle and cartilage $(2,3)$, shell (4) or liver, skin and cartilage (5-7) are used, different processes like de-heading, fileting, skinning and grinding can be employed.

The production of fishmeal (technologies 1' and 2') is carried out in six steps: mincing, cooking, pressing, drying, cooking and grinding. The heating process releases a large amount of liquid, collected to produce fish oil. Oil can also be obtained from fish livers through a grinding process (6'). However, if fishmeal is prepared using crustaceans as raw material there is no oil production. Process $3^{\prime}$ is used to prepare surimi, which implies the treatment of muscle tissue with salt solutions and stabilization with a cryoprotectant. Generally, this is a process with considerable water consumption (Kolbe 1990; Santana et al. 2012). Biopeptides and chondroitin sulphate are produced by enzymatic hydrolysis (Kim and Mendis 2006; Kim and Wijesekara 2010; Ghaly et al. 2013; Arvanitoyannis and Kassaveti 2008; Ferraro et al. 2010), being the process conditions deeply analysed in literature (Rivas et al. 2012; Murado et al. 2009; Ghaly et al. 2013). Chitin was extracted from shell using high temperatures and alkaline extraction (Vazquez et al. 2013). Alkaline extraction was also used to prepare fish gelatine (Harnedy and FitzGerald 2012) .

Several assumptions have been considered in the present work. The case study describes a theoretical situation, where present discarded biomass must be totally unloaded. Changes in the composition of the considered target fisheries and uncertainties of future legislations might lead to a significant variation in the proposed 
case. In addition, economic assessment only includes costs of main process utilities and only water use and $\mathrm{CO}_{2}$ emissions were considered in the environmental assessment. Installation and personnel costs, as well as solid residues derived from processing, were not included in the analysis due to increasing complexity on the network and to data uncertainty. This case study should be seen as a previous situation, which is employed to develop a modelling tool for the selection of the most favourable processing routes of marine biomass.

\section{A Technology Model}

\subsection{Model formulation}

In order to simplify and systematize the selection of optimal pathways to valorise a given amount of discarded species, a simplified general network can be defined (Fig. 2) to represent these valorisation alternatives. In this approach, each layer of the above mentioned superstructure is constituted by $s$ input products or raw materials that can be processed by a set $r$ of defined processing technologies to obtain $v$ final or output products. This formulation allows to easily connect $L$ layers (when further downstream processing is required) by considering the final products of a given layer $l$ the raw material of the next processing network/layer $l+1$. From the above exposed, a general model can be defined to describe the network. Mathematically, the total availability $(Q)$ of discarded biomass is established as:

$$
Q=\sum_{i=1}^{s} q_{i}^{I N}
$$

where $\boldsymbol{q}^{I N}=\left[q_{1}^{I N}, q_{2}^{I N}, \ldots, q_{S}^{I N}\right]^{T} \in \mathbb{R}^{S \times 1}$ is the vector of flow rates of available biomass for each class of raw material. Each element of $q^{I N}$ can be processed by the potential technologies $r$ with the flow rate $\phi_{j}(j=1, \ldots, r)$. Generalizing, we define 
$\boldsymbol{\phi}=\left[\phi_{1}, \phi_{2}, \ldots, \phi_{r}\right]^{T} \in \mathbb{R}^{\mathrm{r} \times 1}$ as the vector of feedstocks's related to a given technology, i.e., the amount of biomass to be processed by it. Mathematically:

$$
\phi_{j}=\sum_{i=1}^{s} a_{i j} \cdot q_{i}^{I N}
$$

being $a_{i j}$ the percentage of raw material $q_{i}^{I N}$ processed by a given technology $j$. For each available biomass, a vector $\boldsymbol{a}_{\boldsymbol{i}}$ is defined as $\boldsymbol{a}_{\boldsymbol{i}}=\left[a_{1 i}, a_{2 i}, \ldots, a_{r i}\right]^{T} \in \mathbb{R}^{r \times 1}$. Extending $\boldsymbol{a}_{\boldsymbol{i}}$ to all available biomasses $(i=1, \ldots, s)$, it is possible to define the following matrix $A=\left(\begin{array}{ccc}a_{11} & \cdots & a_{1 s} \\ \vdots & \ddots & \vdots \\ a_{r 1} & \cdots & a_{r s}\end{array}\right) \in \mathbb{R}^{r \times s}$ whose columns satisfy that $\mathbf{1}^{\boldsymbol{T}} \boldsymbol{a}_{\boldsymbol{i}}=$ $1 \forall i=1, \ldots, s$, i.e. all the biomass $i$ is processed among available processing technologies $r$. These conditions constitute a set of constraints of the optimization problem to be presented later on this work.

Finally, the amount of the different $v$ final products $\left(q_{i}^{\text {OUT }}\right)$ can be easily calculated by considering that the feedstock of a given technology $\phi_{j}$ is processed with a given conversion $b_{k j}$ (yield of the technology) to obtain the referred product $k$. Mathematically:

$$
q_{k}^{\text {OUT }}=\sum_{j=1}^{r} b_{k j} \cdot \phi_{j}
$$

where $\boldsymbol{q}^{\text {oUT }}=\left[q_{1}^{\text {OUT }}, q_{2}^{\text {OUT }}, \ldots, q_{v}^{\text {OUT }}\right]^{T} \in \mathbb{R}^{v \times 1}$ and $\boldsymbol{b}_{\boldsymbol{j}}=\left[b_{1 j}, b_{2 j}, \ldots, b_{v j}\right]^{T} \in \mathbb{R}^{v \times 1}$. In the same way of the definition of matrix $A$ and by extending $\boldsymbol{b}_{\boldsymbol{j}}$ to all available technologies $r$, it is possible to define a matrix of yields for the superstructure as $B=\left(\begin{array}{ccc}b_{11} & \cdots & b_{1 r} \\ \vdots & \ddots & \vdots \\ b_{v 1} & \cdots & b_{v r}\end{array}\right) \in \mathbb{R}^{v \times r}$ 
As mentioned, the presented approach can be easily extended to that cases where more than one class of intermediates/final products and/or more than one processing steps (implying different types of technologies) are required. It is possible to straightforward connect $L$ basic networks as the one described by Equations (1) to (3) on up-down approach by simply defining:

$$
\boldsymbol{q}^{I N}(l+1)=\boldsymbol{q}^{\text {OUT }}(l) \quad \forall l=1, \ldots, L
$$

In the proposed methodology, the core of the approach is the set of technologies, since they are the processing routes that relate in a unidirectional way the raw materials with the final products of the network. Mathematically,

$$
\boldsymbol{q}^{O U T}=B \cdot A \cdot \boldsymbol{q}^{I N}
$$

These technologies can be defined as $\tau\left(q^{I N}, A, B\right)$ and, as shown before, they depend on: i) raw biomasses; ii) the fraction of that input biomasses that are processed by it and; iii) its yield. As a result, these variables and parameters that characterize the technologies could be later used as decision variables to select the optimal valorisation pathways described next.

\subsection{Optimization problem}

In order to evaluate the optimal/best pathways to achieve an integral valorisation of discarded biomass, both economic $\left(J_{\text {eco }}\right)$ and environmental $\left(J_{\text {en }}\right)$ objectives are considered and evaluated through a multi-objective approach, maximizing the first while minimizing the second, respectively.

This a priori complex multi-objective problem can be converted into a set of single-objective problems through the $\varepsilon$-constraint approach (Diwekar 2008; Miettinen 1998), where one of the objectives is incorporated as an inequality constraint. As a consequence, the optimization problem to be solved can be mathematically represented as: 


$$
\max _{X} \boldsymbol{J}=J_{\text {eco }}(\boldsymbol{X})
$$

Subject to:

$$
\begin{gathered}
J_{e n}(\boldsymbol{X}) \leq \epsilon \\
\mathbf{1}^{\boldsymbol{T}} \boldsymbol{X}=s \\
\boldsymbol{q}^{\text {ouT }}(l+1) \leq \boldsymbol{M}_{\boldsymbol{o}}
\end{gathered}
$$

And, subject to the bounds of the problem:

$$
\boldsymbol{X}^{\text {lower }} \leq \boldsymbol{X} \leq \boldsymbol{X}^{\text {upper }}
$$

where $\boldsymbol{X}$ is the decision vector to be found by means the optimization problem and $\boldsymbol{X}^{\text {lower }}, \boldsymbol{X}^{\text {upper }}$ are the lower and upper bounds for the optimization problem, respectively.

Therefore, trade-offs between objectives are represented by the Pareto-front that is calculated by solving the set of single-objective problems presented in Equation (6) subject to (7), (8), (9) and (10) for $\varepsilon$ varying among 0 and 700. It must be highlighted that computing the Pareto-optimal set can be a very challenging task due to the highly constrained and nonlinear nature of processing systems. In this regard, it is important to keep in mind that the majority of the existing implementations to solve this kind of multi-objective problems ultimately rely on local, gradient-based, optimization routines (e.g., sequential quadratic programming - SQP) for solving the NLPs, so they can fail if the multi-objective problem is non-convex and, as a consequence, the solution can only be guaranteed to be local Pareto-optimal. This drawback can be addressed by using suitable global optimization (GO) or evolutionary methods (Sendín et al. 2006). In this aim, the optimal solution of the proposed optimization problem was calculated using scatter search (eSS) as is implemented in the MEIGO toolbox (Egea et al. 2014).

Finally, it must be mentioned that constraint in Equation (9) represents that the amount of final product $\left(\boldsymbol{q}^{\text {oUT }}(l+1)\right)$ obtained by each pathway cannot be higher than the typical plant capacity for that product $\left(\boldsymbol{M}_{\boldsymbol{o}}\right)$. This plant variable is intimately related 
with the market demand since production lines capacities are adapted to the final product requirements of the market. The plant capacity will depend on the location, the final specifications of the products and their applications. Values shown in Table 3 represent typical plant production capacities described in literature.

\subsubsection{Objectives formulation}

The economic part of the objective function represents the given profit of the process, which is defined by the product sales $\left(U_{\text {sales }}\right)$ minus the production costs $\left(J_{P C}\right)$, being the pursued objective:

$$
\max _{X} \quad J_{\text {eco }}=J_{\text {sales }}-J_{P C}
$$

where $\boldsymbol{X}$ are the considered decision variables (one vector per defined processing layer, i.e., $X(1) \forall 1=1, \ldots, L$ ). In this work, the decision vector to be found when solving the optimisation problem will be the set of fractions or percentages of raw material $q_{i}^{I N}$ processed by a given technology $j$ :

$$
\begin{aligned}
& \qquad \boldsymbol{X}^{\boldsymbol{T}}=\left[\boldsymbol{a}_{\mathbf{1}}{ }^{\boldsymbol{T}}, \boldsymbol{a}_{\mathbf{2}}{ }^{\boldsymbol{T}}, \ldots, \boldsymbol{a}_{\boldsymbol{s}}{ }^{\boldsymbol{T}}\right] \in \mathbb{R}^{(r \cdot s) \times 1} \\
& \text { i.e., a vectorization of matrix } A=\left(\begin{array}{ccc}
a_{11} & \cdots & a_{1 s} \\
\vdots & \ddots & \vdots \\
a_{r 1} & \cdots & a_{r s}
\end{array}\right) \in \mathbb{R}^{r \times s} .
\end{aligned}
$$

The economic profit of a given processing technology depends on the market for the associated final product, mainly on its sale price. Therefore, the $J_{\text {sales }}$ can be defined as follows:

$$
J_{\text {sales }}=S^{v^{T}} \cdot q^{\text {ouT }}
$$

where $\boldsymbol{S}^{v} \in \mathbb{R}^{v \times 1}$ is the vector of the market sale prices of the $v$ products (Table 4 ). The prices will strongly depend on the final specifications of the products and their applications, and on the market demand. Values shown in Table 4 represent an average market value. Note that the average prices for BP and CS were estimated using the 
market price of these products in different companies. The production cost term represents the addition of the main costs associated to all technologies leading to the considered final products. These costs include utilities (electricity, water and fuel) and reagents (denoted from now on as $U$ ):

$$
J_{P C}=\boldsymbol{C}^{\boldsymbol{T}} \cdot \boldsymbol{\phi}
$$

$\boldsymbol{C}=\left[C_{1}, C_{2}, \ldots, C_{r}\right]^{T} \in \mathbb{R}^{r \times 1}$ is the cost vector of the considered utilities for each technology $(€ / t)$, that is calculated as:

$$
\boldsymbol{C}^{T}=\boldsymbol{p}^{U^{T}} \cdot \theta^{U}
$$

where $\boldsymbol{p}^{U}=\left[p^{e}, p^{w}, p^{f}, p^{r g}\right]^{T} \in \mathbb{R}^{U \times 1}$ is the price of the utility (electricity ${ }^{1}$, water (Aeas 2010), fuel ${ }^{2}$ and reactive (Sigma-Aldrich 2014)), and $\theta^{U}=\left(\begin{array}{ccc}\theta_{1}^{e} & \cdots & \theta_{r}^{e} \\ \vdots & \ddots & \vdots \\ \theta_{1}^{r g} & \cdots & \theta_{r}^{r g}\end{array}\right) \in$ $\mathbb{R}^{U \times r}$ is the matrix that reflects the amount of utility consumed per ton of biomass by each technology $r$.

From all exposed, the economic objective defined in Equation (12) can be represented on its compact form as:

$$
\begin{aligned}
J_{\text {eco }}=J_{\text {sales }}-J_{P C}= & \boldsymbol{S}^{\boldsymbol{v}^{T}} \cdot\left(B \otimes \boldsymbol{q}^{I N^{T}}\right) \cdot \boldsymbol{X}-\boldsymbol{p}^{\boldsymbol{U}^{T}} \cdot\left(\theta^{U} \otimes \boldsymbol{q}^{I N^{T}}\right) \cdot \boldsymbol{X}= \\
=\left[\boldsymbol{S}^{\boldsymbol{v}^{T}} \cdot\left(B \otimes \boldsymbol{q}^{I N^{T}}\right)-\right. & \left.\boldsymbol{p}^{\boldsymbol{U}^{T}} \cdot\left(\theta^{U} \otimes \boldsymbol{q}^{I N^{T}}\right)\right] \cdot \boldsymbol{X}= \\
& =\left[\boldsymbol{S}^{\boldsymbol{v}^{T}} \cdot Y-\boldsymbol{p}^{U^{T}} \cdot U\right] \cdot \boldsymbol{X}
\end{aligned}
$$

Expression (16) is a general formulation for the case of one layer of processing technologies as the one presented in Fig. 2. It makes use of Kronecker product to define block matrices that allows to use vectorised form of matrix $A$ (vector $\boldsymbol{X}$ ) as decision

\footnotetext{
${ }^{1}$ Peajes y tarifas - Energía Eléctrica - Energía - Ministerio de Industria, Energía y Turismo. Available at: http://www.minetur.gob.es/energia/electricidad/Tarifas/Tarifas2008/Paginas/precios.aspx. (in Spanish).

${ }^{2}$ Precios de carburantes y combustibles. Ministerio de Industría, Energía y Turismo. Available at: http://www.minetur.gob.es/energia/petroleo/Precios/Informes/InformesMensuales/Paginas/IndexInformes Mensuales.aspx (in Spanish).
} 
vector by now defining $\boldsymbol{q}^{\text {OUT }}$ in Equation (5) as $\boldsymbol{q}^{\text {OUT }}=Y \cdot \boldsymbol{X}$ where $Y=\left(B \otimes \boldsymbol{q}^{I \boldsymbol{N}^{T}}\right) \in$ $\mathbb{R}^{v \times(r \cdot s)}$

This basic formulation can be easily extended for the case of multiple connected layers of technologies. For the concrete case study analysed in this work with two layers ( $l$ - raw material pre-processing; and $l+1$ - processing), and by considering Equation (5), the economic objective function presented in Equation (16) can be rewritten as follows:

$$
\begin{gathered}
J_{e c o}=\boldsymbol{S}^{\boldsymbol{v}^{T}}(l+1) \cdot\left(B(l+1) \otimes \boldsymbol{q}^{I N^{T}}(l+1)\right) \cdot \boldsymbol{X}(l+1)-\boldsymbol{p}^{U^{T}} \\
\cdot\left(\theta^{U}(l+1) \otimes \boldsymbol{q}^{I^{T}}(l+1)\right) \cdot \boldsymbol{X}(l+1)= \\
=\left[\boldsymbol{S}^{\boldsymbol{v}^{T}}(l+1) \cdot\left(B(l+1) \otimes(Y(l) \cdot \boldsymbol{X}(l))^{T}\right)-\boldsymbol{p}^{U^{T}}\right. \\
\left.\cdot\left(\theta^{U}(l+1) \otimes(Y(l) \cdot \boldsymbol{X}(l))^{T}\right)\right] \cdot \boldsymbol{X}(l+1)
\end{gathered}
$$

It must be pointed out that the $l+1$ layer has $v$ raw materials, $r$ ' technologies and $v$ ' final products. Therefore, the dimensions of Equation (17) are consistent since $\boldsymbol{S}^{\boldsymbol{v}}(l+1) \in$ $\mathbb{R}^{v \times 1}, \theta^{U}(l+1) \in \mathbb{R}^{U \times r^{\prime}}$ and $\boldsymbol{X}^{\boldsymbol{T}}(l+1) \in \mathbb{R}^{\left(r^{\prime} \cdot v\right) \times 1}$.

In order to simplify, and for the concrete case study analysed in this work, Equation (17) can be re-written in quadratic-like form as:

$$
J_{\text {eco }}=\boldsymbol{X}(\boldsymbol{l}+\mathbf{1})^{\boldsymbol{T}} \cdot\left(C_{V}+C_{U}\right) \cdot \boldsymbol{X}(\boldsymbol{l})
$$

where $C_{V}=\left(\boldsymbol{s}^{v^{T}}(l+1) \cdot B(l+1)\right)^{\boldsymbol{T}} \otimes Y(l) \in \mathbb{R}^{\left(r^{\prime} \cdot v\right) \times(r \cdot s)}$ and $C_{U}=\left(\boldsymbol{p}^{\boldsymbol{U}^{T}}(l+1)\right.$. $\left.\theta^{U}(l+1)\right)^{T} \otimes Y(l) \in \mathbb{R}^{\left(r^{\prime} \cdot v\right) \times(r \cdot s)}$ are matrices of constant parameters of the system (raw material inputs, yields of technologies, sale prices of final products, utility consumptions, etc.) 
Equation (18) can be generalized into a quadratic programming problem with a unique decision vector $\mathrm{X}$ (for all existing layers in the superstructure presented in Figure 1) as follows:

$$
J_{\text {eco }}=\boldsymbol{X}_{\boldsymbol{g}}^{\boldsymbol{T}} \cdot D \cdot \boldsymbol{X}_{\boldsymbol{g}}
$$

where $\boldsymbol{X}_{\boldsymbol{g}}^{\boldsymbol{T}}=\left[\boldsymbol{X}^{T}(l), \boldsymbol{X}^{T}(l+1)\right] \in \mathbb{R}^{\left(r \cdot s+r^{\prime} \cdot v\right) \times 1}$ is the final decision vector of the whole valorising network, $D=\left(\begin{array}{cc}z_{1} & C^{T} \\ C & z_{2}\end{array}\right) \in \mathbb{R}^{\left(r \cdot s+r^{\prime} \cdot v\right) \times\left(r \cdot s+r^{\prime} \cdot v\right)}$ is a square matrix that comprises four sub-matrices: $z_{1} \in \mathbb{R}^{r \cdot s \times r \cdot s}$ and $z_{2} \in \mathbb{R}^{r^{\prime} \cdot v \times r^{\prime} \cdot v}$ are zero matrices and $C=\left(C_{V}+C_{U}\right) \in \mathbb{R}^{\left(r^{\prime} \cdot v\right) \times(r \cdot s)}$.

The environmental impact of each process was characterised by the Ecological Footprint (EF) (Wackernagel and Rees 1996). The EF is an indicator that considers the energy and raw materials fluxes to and from any particular system, converting them into spaces of land or water necessary by nature for producing and/or assimilating these fluxes. In this case, environmental criteria for process selection included $\mathrm{CO}_{2}$ emissions (from electricity and fuel consumption) and water consumption. The calculation of EF implies the conversion of units for these flows to space units, usually hectares (ha). For that purpose, values of energy intensity and natural and/or energy productivity, depending on the case, are required (U.S. EPA 2005; Coto-Millan et al. 2008; Doménech Quesada 2010). Mathematically, this objective can be defined as:

$$
J_{\text {env }}=J_{\mathrm{CO}_{2}}+J_{w}
$$

where the $\mathrm{CO}_{2}$ emission part of the functional $J$ is defined as:

$$
J_{\mathrm{CO}_{2}}=\boldsymbol{E}_{c}^{\boldsymbol{T}} \cdot \boldsymbol{\phi}
$$

In Equation (14), $\boldsymbol{E}_{\boldsymbol{c}}=\left[E_{c 1}, E_{c 2}, \ldots, E_{c r}\right]^{T} \in \mathbb{R}^{r \times 1}$ represents the environmental impact (in ha/year per ton of processed raw material) of the utilities employed by a 
given technology $r$ that result in emissions of $\mathrm{CO}_{2}$ to the atmosphere. Mathematically, $\boldsymbol{E}_{\boldsymbol{c}}$ can be represented as follows:

$$
\boldsymbol{E}_{c}^{T}=\varepsilon^{U^{T}} \cdot \theta_{c}^{U}
$$

where $\varepsilon^{U}=\left[\varepsilon^{e}, \varepsilon^{f}\right]^{T} \in \mathbb{R}^{2 \times 1}$ is the equivalence factor of the utilities consumed in terms of amount of $\mathrm{CO}_{2}$ emitted to the atmosphere and $\theta_{c}^{U}=\left(\begin{array}{ccc}\theta_{1}^{e} & \cdots & \theta_{r}^{e} \\ \theta_{1}^{f} & \cdots & \theta_{r}^{e}\end{array}\right) \in$ $\mathbb{R}^{2 \times r}$ is the matrix that reflects the amount of utilities that have associated $\mathrm{CO}_{2}$ emissions, consumed per ton of biomass by each technology $r$. As mentioned, two utilities are considered (electricity - $e$; and fuel - $f$ ) in this work to calculate the environmental impact of $\mathrm{CO}_{2}$ emissions. When the utility considered is electricity, $\varepsilon^{e}$ is the amount of $\mathrm{CO}_{2}$ emitted to the atmosphere equivalent to the $\mathrm{KWh}$ of electricity consumed in each technology (DEFRA 2012), expressed in ha/y (Coto-Millan et al. 2008). In the same way, the conversion factor $\varepsilon^{f}$ is the amount of $\mathrm{CO}_{2}$ emitted to the atmosphere equivalent to the $\mathrm{kg}$ of fuel consumed in each technology (U.S. EPA 2005), expressed in ha/y (Coto-Millan et al. 2008).

In a similar way, the term $J_{w}$ represents the environmental impact of the water consumed during the production processes/technologies. By applying Equations (21) and (22), $J_{w}$ can be defined as:

$$
\begin{array}{r}
J_{w}=\boldsymbol{E}_{w}^{T} \cdot \boldsymbol{\phi} \\
\boldsymbol{E}_{w}^{T}=\varepsilon^{w} \cdot \boldsymbol{\theta}^{\boldsymbol{w}^{T}}
\end{array}
$$

where $\theta^{w}=\left[\theta_{1}^{w}, \theta_{2}^{w}, \ldots, \theta_{r}^{w}\right]^{T} \in \mathbb{R}^{r \times 1}$ is the water consumption of the $r$ technologies described in Table 2, and $\varepsilon^{w}$ represent a conversion factor from water consumed to equivalent hectares (Doménech Quesada 2010).

By introducing Equations (21) to (24) into (20), the general environmental objective can be defined as: 


$$
\begin{gathered}
J_{e n}=J_{C O_{2}}+J_{w}=\left(\left(\varepsilon^{U^{T}} \cdot \theta_{c}^{U}\right) \otimes \boldsymbol{q}^{I N^{T}}\right) \cdot \boldsymbol{X}+\left(\left(\varepsilon^{w} \cdot \boldsymbol{\theta}^{w^{T}}\right) \otimes \boldsymbol{q}^{I N^{T}}\right) \cdot \boldsymbol{X} \\
=\left[\left(\left(\varepsilon^{U^{T}} \cdot \theta_{c}^{U}\right) \otimes \boldsymbol{q}^{I N^{T}}\right)+\left(\left(\varepsilon^{w} \cdot \boldsymbol{\theta}^{\boldsymbol{w}^{T}}\right) \otimes \boldsymbol{q}^{I N^{T}}\right)\right] \cdot \boldsymbol{X}
\end{gathered}
$$

For the particular two layer problem analysed in this work, Equation (25) should be rewritten as:

$$
\begin{aligned}
& J_{e n}=\left[\left(\left(\varepsilon^{U^{T}}(l+1) \cdot \theta_{c_{2}}^{U}(l+1)\right) \otimes(Y(l) \cdot X(l))^{T}\right)+\right. \\
& \left.+\left(\varepsilon^{w}(l+1) \cdot \boldsymbol{\theta}^{\boldsymbol{w}^{T}}(l+1)\right) \otimes(Y(l) \cdot \boldsymbol{X}(l))^{T}\right] \cdot \boldsymbol{X}(l+1)
\end{aligned}
$$

Analogously to Equation (18), last expression can be expressed in a compact form for the analysed case study:

$$
J_{e n v}=\boldsymbol{X}(\boldsymbol{l}+\mathbf{1})^{\boldsymbol{T}} \cdot\left(E_{C}+E_{w}\right) \cdot \boldsymbol{X}(\boldsymbol{l})
$$

being $E_{C}=\left(\varepsilon^{U^{T}}(l+1) \cdot \theta_{c_{2}}^{U}(l+1)\right)^{T} \otimes Y(l) \in \mathbb{R}^{\left(r^{\prime} \cdot v\right) \times(r \cdot s)}$ and $E_{W}=\left(\varepsilon^{w}(l+1)\right.$. $\left.\boldsymbol{\theta}_{\boldsymbol{w}}^{\boldsymbol{T}}(l+1)\right)^{\boldsymbol{T}} \otimes Y(l) \in \mathbb{R}^{\left(r^{\prime} \cdot v\right) \times(r \cdot s)}$ constant matrices.

As for the economic objective case, a quadratic form of Equation (27) can be straightforward defined as:

$$
J_{e n v}=X_{g}^{T} \cdot G \cdot X_{g}
$$

where $G=\left(\begin{array}{cc}z_{1} & E^{T} \\ E & z_{2}\end{array}\right) \in \mathbb{R}^{\left(r \cdot s+r^{\prime} \cdot v\right) \times\left(r \cdot s+r^{\prime} \cdot v\right)}$ with $E=\left(E_{C}+E_{W}\right) \in \mathbb{R}^{\left(r^{\prime} \cdot v\right) \times(r \cdot s)}$.

From all exposed, the multi-objective optimization problem presented in Equation (6) subject to constraints (7), (8), (9) and (10) can be defined as a quadratically constrained quadratic programming (QCQP) since both $J_{\text {eco }}$ as well as one of the restrictions (resulting from substituting Equation 28 into Equation 7) are quadratic functions.

In general, QCQPs are non-convex. Therefore, there is a lack of computationally efficient solution methods. In this aim, there is a large literature on optimal or approximate algorithms for QCQPs, mainly focused on the relaxation of these 
problems, like the semidefinite programming or SDP [59]. Such semidefinite programs are solvable in polynomial time using interior-point methods if and only if matrices D and $\mathrm{G}$ are positive-definite matrices. For the proposed case study, D and $\mathrm{G}$ do not satisfy this condition.

Therefore, and as mentioned before at the end of Section 3.1, an evolutionary algorithm like $e S S$ has been used instead of traditional analytic methods like Lagrange Multipliers or available SQP algorithms/implementations in order to avoid problems due to the possible non-convexity of the defined multi-objective problem.

\section{Results and discussion}

Once the economic and environmental objectives have been defined, the solutions were obtained using the optimization strategy presented above. Main results for the three different kinds of biomass are presented in this section.

\subsection{Valorisation of fish biomass (A)}

This class of biomass is the most discarded in the analysed case study (in terms of total tonnes of biomass), and mainly two different strategies are used for valorising: a) using the whole specimen for fish meal production, obtaining fish oil as subproduct or; $b$ ) using only parts of the fish (in this case muscle) as sources of surimi and BP.

The optimal pathway configuration from an economic point of view is shown in Fig. 3.A. This processing pathway configuration with a higher economic profit is related to the valorisation of specific fish fractions (muscle) rather than the use of the whole specimen. In the optimal economic solution, the obtained muscle is used as raw material to obtain BP at the maximum plant capacity, and the excess of raw material is incorporated to the production of FM and FO. Also note that lowest production costs $\left(J_{P C}\right)$ correspond to the most profitable pathway. 
From an environmental point of view, the optimal scenario corresponds to the no processing of biomass (Fig. 3.B). In this context, it is straightforward to say that the pathway configuration with less impact is that which transforms the biomass through the grinding process $(j=1)$. However, this configuration has an additional environmental and economic impact due to the need of processing remaining fish biomass as a solid waste. Since the valorisation of biomass to obtain a product is a sine qua non condition of the present case study, an analysis of the combinations that are forced to obtain products reveals that the optimal environmental solution is the one that process at least $80 \%$ of the biomass to obtain $\mathrm{BP}$ as product and leaves the reaming biomass unprocessed.

If both economic and environmental criteria are considered (Fig. 3.C), the obtained set of solutions present two different areas. In the right area, when the environmental cost increase, the profit of the pathway decrease, that is, both criteria are inadequate. The pathway configuration changes from producing mainly BP to produce FM/FO. All solutions that produce FM/FO at full plant capacities present a reduction on the profit due to the high production costs generated by fuel purchase (Vazquez et al. 2013). Therefore, an alternative energy source should be considered. Also note that the impact of FM/FO process, ten times bigger than BP production, is due to the important effect of the use of fuel as energy source.

It is interesting to note the preference of producing BP rather than surimi, since this product increases $J_{e n}$ up to a $50 \%$ when compared with those pathways producing BP. This is because BP and have less environmental impact than the production of surimi. An analysis of the impact generated by water consumption reveals that producing surimi at maximum plant capacity has a large water impact $\left(J_{w}\right)$. Moreover, the impact generated by electric consumption $\left(J_{e}\right)$ is also higher in those combinations producing surimi than in those producing BP. 
In the left area (Fig. 3.C), an increase of the environmental cost is related with an increased profit. Pathways with low environmental cost have as well low profit values, and also leave large amounts of unprocessed biomass. This biomass must be treated as solid waste. In order to include the extra economic and environmental impact associated to this additional process (incineration was selected as reference waste management process), the pathway scheme and the problem formulation was modified, including the environmental cost of transporting and incinerating the solid waste. Mathematically:

$$
J_{\text {waste }}=J_{\text {trans }}+J_{\text {inc }}
$$

With

$$
J_{\text {trans }}=d \cdot n t \cdot c_{\text {truck }} \cdot \varepsilon^{f}
$$

representing the $\mathrm{CO}_{2}$ emission generated by the transport of the solid waste to the nearest processing plant (with a distance from the biomass generating points and back of $d=270 \mathrm{~km} /$ round trip), 20 days per month during a year (therefore, $n t=240$ round trips), in a truck with a transporting capacity of $3,000 \mathrm{~kg}$ of biomass. In average, this kind of transport consumes 401 of fuel every $100 \mathrm{~km}\left(c_{\text {truck }}\right)$.

The second term of Equation (29) $\left(J_{\text {inc }}\right)$ corresponds to the $\mathrm{CO}_{2}$ emission due to the incineration process.

$$
J_{i n c}=\sum_{r} \boldsymbol{q}^{u n p} \cdot \theta_{i n c}^{e} \cdot \varepsilon^{e}
$$

$\boldsymbol{q}^{u n p}=\left[q_{1}^{u n p}, q_{2}^{u n p}, \ldots, q_{r}^{u n p}\right]^{T} \in \mathbb{R}^{r \times 1}$ is the amount of biomass left unprocessed by a given technology and $\theta_{i n c}^{e}$ corresponds with the $\mathrm{kWh}$ consumed to incinerate 1 tonne of material (Geng et al 2010). 
Incinerating and transporting the solid waste has also an economic cost. However, this cost was considered negligible when compared with the profits of the process $(2,000$ times lower). The new set of solutions is presented in Fig. 3.D. It can be observed that the environmental cost of those situations that leave biomass unprocessed is increased in the range of a 10 to $25 \%$, depending on the amount of unprocessed biomass. This fact implies the translation of the graphical solutions of these scenarios to the right. However, the optimal valorising configurations are not modified, i.e., producing $\mathrm{BP}$ and as main products, and the remaining biomass being left as unprocessed muscle.

\subsection{Valorisation of crustacean biomass $(B)$}

As shown in Section 2.1 (Table 1), one of the most discarded groups in the selected fisheries is crustacean species (Polybius henslowii and Munida spp.). There are two typical alternatives for valorising this particular biomass: i) obtaining of chitin/chitosan and ii) fish meal production (Fig. 2, section B). Chitin is present in the shell of crustaceans on a $25-30 \%$ of the total dry weight of the specimen (Hayes 2012). Therefore, a pre-treatment stage where shells are separated from the body to obtain the specific raw material is required. On the other hand, crustacean meal is obtained from the whole specimen. Technologies and resources for these processes are summarized in Table 2.

If the different combinations for the treatment of crustaceans are mathematically analysed, two opposite trends are observed from an economic point of view. The more interesting technology is the production of chitin, since the sales price of this final product is significantly high (Table 3 ). Therefore, those combinations implying more

chitin production will be the most economically profitable, although they have associated a high environmental impact due to their large consumption of utilities. However, the obtaining of FM is not an advantageous alternative to the chitin pathway, 
due to the higher $J_{e n}$ caused by the fuel use. As mentioned in the case of Biomass A, the environmentally advantageous solutions match with the ones where minimum addedvalue product is obtained (Fig. 4.A). However, these situations have an extra economic and environmental impact related to the solid waste treatment of unprocessed biomass. The set of solutions considering both criteria simultaneously is presented in the Paretofront of Fig. 4.B. If the profit of the pathway increases, the environmental cost also increases. In these configurations, shells are used to produce chitin, avoiding FM as final product (Fig. 4.C). A reduction on the environmental cost means a reduction on the amount of Chitin obtained, and thus a reduction on profits. The area defined between $30 \leq J_{\text {en }} \leq 50\left(\frac{h a}{\text { year }}\right)$ and $0.75 \cdot 10^{6} \leq J_{\text {eco }} \leq 1.75 \cdot 10^{6}\left(\frac{€}{\text { year }}\right)$ ensures the best compromise between both pursued objectives. The optimal pathway configuration (Fig. 4.D) is to use shells to obtain chitin as final product against the production of FM and leave biomass unprocessed.

These optimal configurations leave a high percentage of raw material untreated (up to the $60 \%$ of the initial biomass), since the production of chitin only uses the shells. Therefore, the non-used parts could be incorporated to a crustacean meal line, as discussed below (Fig. 4.E). This formulation enhances the profits of this technology but also increases its environmental cost. This is reflected in a change of the Pareto configuration (Fig. 4.F), where two areas are now observed. In the area where $J_{e n}$ is up to 90 ha/year, chitin and FM are obtained as final products. In the other area, only chitin is obtained as product. Focusing on the area with better relationship between objectives, a moderate production of chitin together with leaving a fraction of biomass unprocessed would be the best combination. Therefore, and as in the previous case, $J_{\text {waste }}$ was incorporated to the analysis. When considering this additional term (Fig. 4.G), the pathways that transform $13-20 \%$ of biomass into chitin still have the better relationship between objectives (Fig. 4.H). In case that the objective was to transform all the 
crustacean biomass into chitin, more environmentally friendly technologies for the conversion of the shell into chitin should be considered, as it is proposed in Vazquez et al. (Vazquez et al. 2013).

\subsection{Valorisation of cartilaginous biomass (C)}

Note that from the initial cartilaginous biomass (whole specimens of small-spotted catshark and black-mouthed dogfish species) only three fractions are considered as raw material for valorisation (Fig. 1): liver, skin and cartilage (Ordóñez-Del Pazo et al. 2014). The remaining fraction (mainly muscle) is not included in the proposed valorising network since it is destined for direct human consumption. Pre-processing technologies yield a biomass percentage of the total specimen, according to the considered fraction. In general, only fish oil was obtained from liver, but recently, several studies have shown the interest of extracting enzymes from this viscera (Ordóñez-Del Pazo et al. 2014; Arvanitoyannis and Kassaveti 2008; Ghaly et al. 2013; Ascanio et al. 2004). The skins represent a $11 \%$ of the total body of sharks (Nomura 2004), being an excellent source of collagen (Antelo et al. 2007; Ordóñez-Del Pazo et al. 2014). Additionally, CS can be obtained from the cartilage ( Murado et al. 2010). The mathematical analysis of the valorisation alternatives is presented in Fig. 5.A. As in the previous cases, the environmental optimal solution is to not process any biomass (Fig. 5.B). From an economic point of view, the most profitable combination of technologies implies the valorisation of livers as enzymes and the production of CS and gelatine from cartilage and skin, respectively (Fig. 5.C). If both criteria are considered (Fig. 5.A), the optimal pathway configurations are those that produce fish enzymes, CS and leave unprocessed raw material (Fig. 5.D). Due to the bad relationship between criteria, the optimization system reduces $J_{e n}$ by stopping the production of gelatine in 
the first place. Avoiding gelatine as final product is reflected in a large reduction of $J_{e n}$ (more than 60\%), while the impact on the profit is less than $1 \%$. If $J_{\text {waste }}$ is considered as in the previous cases, the new set of solutions (Fig. 5.E) shows that the environmental cost of those pathways with unprocessed material has increased around $10-15 \%$. However, this rise is insignificant when compared with the environmental cost of producing gelatine. If gelatine was a product of main interest, a more environmentally friendly process (Karim and Bhat 2009) than those state-of-art considered in this work, should be implemented.

Therefore, the optimal set of pathways is the one that transforms as much as liver as possible into enzymes and cartilage into CS, and sends the unprocessed material to solid waste treatment (Fig. 5.F). However, producing CS from cartilaginous species as an additional source could present an advantage that should be analysed. The maximum capacity of CS production from cartilaginous species is $162 \mathrm{t}$, which is below the typical maximum plant capacity (Table 4). To increase the production capacity to $200 \mathrm{t}$ of this valuable product, other sources of cartilaginous species (from other métiers, near ports or processing industries) should be considered simultaneously. In this case, the products presented in the optimal set of pathways are enzymes, BP and CS. Note that when BP or CS are produced, there is an increase on profits around a 5$10 \%$, compared with the case where enzymes are the only product. However, producing $\mathrm{BP}$ and CS also increase the environmental cost in a $20 \%$. As in the fish case, the excess of muscle obtained is processed as surimi (increasing the profit around a $2 \%$ and the environmental impact in a 10\%). The optimal set of pathways avoids the large production of FM/FO and gelatine due to the high environmental impact derived from fuel use $(F M / F O)$ and from the high electric and water consumption of technology $\mathrm{j}^{\prime}=1$, respectively.

\subsection{Re-design of technologies}


The formulation presented in this work allows knowing how certain parameters should be modified (utilities consumptions, yield, etc.) in order to include this technology in the optimal set of pathways. For example, a yield up to $30 \%$ in $\mathrm{j}^{\prime}=1$ would modify the optimal product configuration in the case of biomass A, being the production of FM/FO an interesting product from an economic point of view. Similarly, a yield of $40 \%$ in technologies $\mathrm{j}^{\prime}=2$ implies that the use of crustacean biomass to produce $\mathrm{FM} / \mathrm{FO}$ would be a profitable technology. However, a yield up to the $70 \%$ would be needed to compensate the high environmental cost of producing gelatine, due to the high utilities consumption of this process.

\section{Conclusions}

In this work, a processing network for the valorisation of discarded biomass in selected métiers of NW Spain is proposed. A mathematical model for the optimisation of the developed structure was constructed based on environmental and economic objectives. Biomass was divided and analysed in three groups: fish, crustaceans and cartilaginous species. Main results show that, in general, the most optimal processing routes correspond to the obtaining of high-added value products (biopeptides, enzymes and chondroitin sulphate), not only for their high sale prizes, but also for the lower environmental impact associated with their production processes when compared with the other products that can be obtained in the proposed valorising network. However, CS production should be considered with caution, since the production obtained was much lower than the plant production capacity. In this case, more biomass (from other métiers or fish processing industries) would be necessary to improve the optimal behaviour of the valorising network. Fishmeal and oil, chitin and gelatine were not the preferable choices due mainly to their high associated $\mathrm{CO}_{2}$ emission and water consumption. In fact, the developed system opts for leaving unprocessed biomass and managed it as a residue, rather than producing those products in proposed optimal 
pathway configurations. However, these useful products are object of interest and necessary for many industrial applications, like for example fishmeal and oil, essentially in aquaculture. Thus, resources reduction and optimisation of these processes will be a necessary step for including them in valorising networks of marine biomass, which are developed according to industrial ecology principles.

\section{Acknowledgements}

The authors acknowledge the financial support received from the European Union through the LIFE Environment Program of the European Union (LIFE05 ENV/E000267-BE FAIR,LIFE08 ENV/E/000119-FAROS and LIFE13 ENV/ES/000131-LIFE iSEAS). Dr. Amaya Franco-Uría would like to thank Secretaría de Estado de Investigación, Desarrollo e Innovación for the support provided by the “Ramón y Cajal” Subprogram.

\section{References}

Aeas. 2010. Tarifas de Agua En España 2009: Precio de Los Servicios de Abastecimiento y Saneamiento. Asociación Española de abastecimiento y saneamiento.

Alonso, A.A., Antelo L.T., Otero-Muras I., and Pérez-Gálvez R. 2010. "Contributing to Fisheries Sustainability by Making the Best Possible Use of Their Resources: The BEFAIR Initiative." Trends in Food Science \& Technology 21 (11): 569-78. doi:10.1016/j.tifs.2010.07.011.

Antelo, L.T., Pérez-Martín, R.I., and Alonso, A.A. 2007. Deliverable 4.1. Input Output Tables for the Different Processes. Deliverable. BE-FAIR PROJECT (LIFE5 ENV/E000267-BEFAIR).

Arunchalam, K., and Haard, N.F. 1985. "Isolation and Characterization of Pepsin from Polar Cod (Boreogadus Saida)." Comparative Biochemistry and Physiology Part B: Comparative Biochemistry 80 (3): 467-73. doi:10.1016/0305-0491(85)90274-3.

Arvanitoyannis, I.S., and Kassaveti, A. 2008. "Fish Industry Waste: Treatments, Environmental Impacts, Current and Potential Uses." International Journal of Food Science \& Technology 43 (4): 726-45. doi:10.1111/j.1365-2621.2006.01513.x. 
Ascanio, G., Castro, B., and Galindo, E. 2004. "Measurement of Power Consumption in Stirred Vessels-a Review." Chemical Engineering Research and Design 82 (9 SPEC. ISS.): 1282-90. doi:10.1205/cerd.82.9.1282.44164.

Batista, I., and Pires, C. 2002. "Comparative Studies of the Proteolytic Activity of Crude Extracts from the Digestive Tract of Three Shark Species." Journal of Aquatic Food Product Technology 11 (3-4): 151-65. doi:10.1300/J030v11n03_12.

Bernardi, A., Giarola, S., and Bezzo, F.. 2013. "Spatially Explicit Multiobjective Optimization for the Strategic Design of First and Second Generation Biorefineries Including Carbon and Water Footprints." Industrial and Engineering Chemistry Research 52 (22): 7170-80. doi:10.1021/ie302442j.

Blanco, M., Sotelo, C. G., Chapela M. J., and Pérez-Martín, R.I. 2007. "Towards Sustainable and Efficient Use of Fishery Resources: Present and Future Trends." Trends in Food Science \& Technology 18 (1): 29-36. doi:10.1016/j.tifs.2006.07.015.

Capasso, C., Lees W.E., Capasso, A., Scudiero R., Carginale, V., Kille, P., Kay. J., and Parisi, E. 1999. "Cathepsin D from the Liver of the Antarctic Icefish Chionodraco Hamatus Exhibits Unusual Activity and Stability at High Temperatures." Biochimica et Biophysica Acta (BBA) - Protein Structure and Molecular Enzymology 1431 (1): 64-73. doi:10.1016/S0167-4838(99)00039-4.

Coto-Millan, P., Doménech Quesada, J.L., and Mateo Mantecon, I. 2008. "Corporate Ecological Footprint: New Conversion Factors." International Journal of Ecology 2008 (October): e415934. doi:10.1155/2008/415934.

DEFRA. 2012. Guidelines to Defra / DECC's GHG Conversion Factors for Company Reporting.

Diwekar, U. 2008. Introduction to Applied Optimization. Vol. 22. Springer Optimization and Its Applications. Springer.

Doménech Quesada, J. L. 2010. Carbon Footprint-Corporate Ecological Footprint (MC3 Methodology). http://www.huellaecologica.com.

European Commission, 2013. Regulation (EU) No 1380/2013 of the European Parliament and the Council of 11 December 2013 on the Common Fisheries Policy, amending Council Regulations (EC) No 1954/2003 and (EC) No 1224/2009 and repealing Council Regulations (EC) No 2371/2002 and (EC) No 639/2004 and Council Decision 2004/585/EC.

Available at: http://ec.europa.eu/fisheries/cfp/index_en.htm

Egea, J.A. 2008. "New Heuristics for Global Optimization of Complex Bioprocesses." Vigo: Universidad de Vigo.

Egea, J.A., Rodríguez-Fernández M., Banga, J.R., and Martí R. 2007. "Scatter Search for Chemical and Bio-Process Optimization." Journal of Global Optimization 37 (3): 481-503. doi:10.1007/s10898-006-9075-3.

Egea, J. A., Henriques D., Cokelaer, T., Villaverde, A.F., MacNamara, A., Danciu, D.P, Banga, J.R., and Saez-Rodriguez, J. 2014. "MEIGO: An Open-Source Software Suite 
Based on Metaheuristics for Global Optimization in Systems Biology and Bioinformatics.” BMC Bioinformatics 15 (1): 136. doi:10.1186/1471-2105-15-136.

El-Halwagi, A.M., Rosas, C., Ponce-Ortega, J.M., Jiménez-Gutiérrez, A., Mannan, M.S., and El-Halwagi, M.M. 2013. "Multiobjective Optimization of Biorefineries with Economic and Safety Objectives." AIChE Journal 59 (7): 2427-34. doi:10.1002/aic.14030.

Eysturskarð, J. 2010. "Production of Collagen/gelatin from Fish Skin in the Faroe Islands in the Faroe Islands." In . Stjørdal (Norway). http://www.rubin.no/konferansen10/foredrag/Jonhard_Eysturskard.pdf.

FAO. 1986. "The Production of Fish Meal and Oil - Contents." http://www.fao.org/docrep/003/x6899e/x6899e00.htm.

FAO Fisheries and Aquaculture Department. 2012. The State of World Fisheries and Aquaculture. Rome: Food and Agriculture Organization of the United Nations.

Ferraro, V., Cruz, I.B, Jorge, R.F., Malcata, F.X., Pintado, M.E., and Castro, P.M.L. 2010. "Valorisation of Natural Extracts from Marine Source Focused on Marine byProducts: A Review." Food Research International 43 (9): 2221-33. doi:10.1016/j.foodres.2010.07.034.

Freitas, A. C., Rodrigues, D., Rocha-Santos T.A.P., Gomes, A.M.P., and Duarte, A.C. 2012. "Marine Biotechnology Advances towards Applications in New Functional Foods." Biotechnology Advances, Special issue on ACB 2011, 30 (6): 1506-15. doi:10.1016/j.biotechadv.2012.03.006.

FROM. 2009. Technical Paper on "Asistencia Técnica Para La Realización de Una Medida Innovadora Para La Recuperación, Gestión Y Valorización de Los Descartes Generados Por La Flota Española Que Faena En Los Caladeros Atlántico Y Mediterráneo". $\quad$ http://www.from.es/multimedia/RESUMEN\%2520AMPLIO_tcm8539779.pdf.

Gebreslassie, B.H., Slivinsky, Wang, M.B., and You, F. 2013. "Life Cycle Optimization for Sustainable Design and Operations of Hydrocarbon Biorefinery via Fast Pyrolysis, Hydrotreating and Hydrocracking." Computers and Chemical Engineering 50: 71-91. doi:10.1016/j.compchemeng.2012.10.013.

Geng, Y., Tsuyoshi F., and Chen, F.. 2010. "Evaluation of Innovative Municipal Solid Waste Management through Urban Symbiosis: A Case Study of Kawasaki." Journal of Cleaner Production 18 (10-11): 993-1000. doi:10.1016/j.jclepro.2010.03.003.

Gerber, L., Fazlollahi, S., and Maréchal, F. 2013. "A Systematic Methodology for the Environomic Design and Synthesis of Energy Systems Combining Process Integration, Life Cycle Assessment and Industrial Ecology." Computers \& Chemical Engineering 59 (December): 2-16. doi:10.1016/j.compchemeng.2013.05.025.

Ghaly, A.E, Ramakrishnnan V.V., Brooks M.S., Budge, S.M., and Dave, D.. 2013. "Fish Processing Wastes as a Potential Source of Proteins, Amino Acids and Oils: A Critical Review." Journal of Microbial \& Biochemical Technology 5(4) (November): 107-29. doi:10.4172/1948- 5948.1000110. 
Gildberg, A. 2002. Enhancing Returns from Greater Utilization. In: Safety and Quality Issues in Fish Processing. Safety and Quality Issues in Fish Processing. Cambridge, England: Woodhead Publishing Limited.

Gutiérrez-Arriaga, C.G., Serna-González, M., Ponce-Ortega, J.M., and El-Halwagi, M.M. 2014. "Sustainable Integration of Algal Biodiesel Production with Steam Electric Power Plants for Greenhouse Gas Mitigation." ACS Sustainable Chemistry and Engineering 2 (6): 1388-1403. doi:10.1021/sc400436a.

Harnedy, P. A., and FitzGerald, R.J. 2012. "Bioactive Peptides from Marine Processing Waste and Shellfish: A Review." Journal of Functional Foods 4 (1): 6-24. doi:10.1016/j.jff.2011.09.001.

Hayes, M. 2012. Chitin, Chitosan and Their Derivatives from Marine Rest Raw Materials: Potential Food and Pharmaceutical Applications. Marine Bioactive Compounds: Sources, Characterization and Applications. Springer.

Karim, A. A., and Bhat, R. 2009. "Fish Gelatin: Properties, Challenges, and Prospects as an Alternative to Mammalian Gelatins." Food Hydrocolloids 23 (3): 563-76. doi:10.1016/j.foodhyd.2008.07.002.

Kasivisvanathan, H., Ng, R.T.L, Tay, D.H.S., and Ng D.K.S. 2012. "Fuzzy Optimisation for Retrofitting a Palm Oil Mill into a Sustainable Palm Oil-Based Integrated Biorefinery." Chemical Engineering Journal 200-202: 694-709. doi:10.1016/j.cej.2012.05.113.

Kelleher, K. 2005. Discards in the World's marine Fisheries: An Update. FAO Fisheries Technical Paper No. 470. Food and Agricultural Organization of the United Nations, Rome, Italy.

Kelloway, A., and Daoutidis, P. 2014. "Process Synthesis of Biorefineries: Optimization of Biomass Conversion to Fuels and Chemicals." Industrial and Engineering Chemistry Research 53 (13): 5261-73. doi:10.1021/ie4018572.

Kim, S.K. 2012. Marine Medicinal Foods Implications and Applications - Animals and Microbes. Advances in Food and Nutrition Research 65. Academic Press.

Kim, S.K., and Mendis, E. 2006. "Bioactive Compounds from Marine Processing Byproducts - A Review." Food Research International 39 (4): 383-93. doi:10.1016/j.foodres.2005.10.010.

Kim, S. K., and Wijesekara, I. 2010. "Development and Biological Activities of Marine-Derived Bioactive Peptides: A Review." Journal of Functional Foods 2 (1): 19. doi:10.1016/j.jff.2010.01.003.

Kolbe, E. 1990. "Estimating ENERGY CONSUMPTION IN SURIMI PROCESSING." Applied Engineering in Agriculture 6 (3): 322-28. doi:0883-8542 / 90 / 0603-0322.

Kurita, K. 2006. "Chitin and Chitosan: Functional Biopolymers from Marine Crustaceans." Marine Biotechnology 8 (3): 203-26. doi:10.1007/s10126-005-0097-5. 
Lerner. 1998. "Chitin and Chitosan Markets Set For Capacity Shot by New Player." http://www.icis.com/resources/news/1998/01/05/85917/chitin-and-chitosan-marketsset-for-capacity-shot-by-new-player/.

Lopes, C., Antelo, L.T., Franco-Uría, A., Alonso, A.A., and Pérez-Martín R.I. 2012. "Environmental Impacts of a Fishmeal Processing Factory: Advantages of Discards Valorization against Disposal.” In .

Mahro, B., and Timm, M.. 2007. "Potential of Biowaste from the Food Industry as a Biomass Resource." Engineering in Life Sciences 7 (5): 457-68. doi:10.1002/elsc.200620206.

Martinez-Hernandez, E., Campbell G.M., and Sadhukhan J. 2014. "Economic and Environmental Impact Marginal Analysis of Biorefinery Products for Policy Targets." Journal of Cleaner Production 74: 74-85. doi:10.1016/j.jclepro.2014.03.051.

Martinez-Hernandez, E., Campbell, G., and Sadhukhan, J. 2013. "Economic Value and Environmental Impact (EVEI) Analysis of Biorefinery Systems." Chemical Engineering Research and Design 91 (8): 1418-26. doi:10.1016/j.cherd.2013.02.025.

Miettinen, K. 1998. Nonlinear Multiobjective Optimization. Vol. 12. International Series in Operations Research \& Management Science. Spinger. http://www.springer.com/business $+\% 26+$ management/operations + research/book/978-07923-8278-2.

Murado, M.A., González M.D.P., and Vázquez, J.A. 2009. "Recovery of Proteolytic and Collagenolytic Activities from Viscera by-Products of Rayfish (Raja Clavata)." Marine Drugs 7 (4): 803-15. doi:10.3390/md7040803.

Murado, M.A., Fraguas, J., Montemayor, M.I., Vázquez J. A., and González, P. 2010. "Preparation of Highly Purified Chondroitin Sulphate from Skate (Raja Clavata) Cartilage by-Products. Process Optimization Including a New Procedure of Alkaline Hydroalcoholic Hydrolysis." Biochemical Engineering Journal 49 (1): 126-32. doi:10.1016/j.bej.2009.12.006.

Murillo-Alvarado, P.E., Ponce-Ortega, J.M., Serna-González, M., Castro-Montoya, A.J., and El-Halwagi, M.M. 2013. "Optimization of Pathways for Biorefineries Involving the Selection of Feedstocks, Products, and Processing Steps." Industrial and Engineering Chemistry Research 52 (14): 5177-90. doi:10.1021/ie303428v.

Murillo-Alvarado, P.E., Santibañez-Aguilar, J.E., Ponce-Ortega, J.M., Castro-Montoya A.J., Serna-González, M., and El-Halwagi, M.M. 2014. "Optimization of the Supply Chain Associated to the Production of Bioethanol from Residues of Agave from the Tequila Process in Mexico." Industrial and Engineering Chemistry Research 53 (13): 5524-38. doi:10.1021/ie4031715.

Ng, R.T.L., Hassim, M.H., and.Ng, D.K.S. 2013. "Process Synthesis and Optimization of a Sustainable Integrated Biorefinery via Fuzzy Optimization." AIChE Journal 59 (11): 4212-27. doi:10.1002/aic.14156.

Nomura, Y. 2004. "Properties and Utiliztion of Shark Collagen." In More Efficient Utilization of Fish and Fisheries Products, edited by M. Sakaguchi, 42:147-58. Amsterdam: Elsevier Science Bv. 
Olsen, R. L., Toppe, J., and Karunasagar, I. 2014. "Challenges and Realistic Opportunities in the Use of by-Products from Processing of Fish and Shellfish." Trends in Food Science \& Technology 36 (2): 144-51. doi:10.1016/j.tifs.2014.01.007.

Ordóñez-Del Pazo, T., Antelo, L.T., Franco-Uría, A., Pérez-Martín R.I., Sotelo, C.G., and Alonso, A. A. 2014. "Fish Discards Management in Selected Spanish and Portuguese Métiers: Identification and Potential Valorisation." Trends in Food Science \& Technology 36 (1): 29-43. doi:10.1016/j.tifs.2013.12.006.

Pangsorn, S., Laong-Manee, P., and Siripaksophon, S. 2007. Status of Surimi Industry in the Southeast Asia. Southeast Asian Fisheries Developement Center. http://map.seafdec.org/downloads/pdf/publicationsurimimile/Report_Status\%20of\%20Surimi_Part1_final_ed2.pdf.

Park, J.W. 2005. Surimi and Surimi Seafood. 2nd ed. Food Science and Technology 142. Taylor \& Francis.

Rivas, D., Antelo, L.T., Balsa-Canto, E., and Alonso, A.A. 2012. "Kinetic Parameter Estimation as a Tool for Optimal Enzymatic Hydrolysis of Discarded Crustaceans in North Atlantic Fisheries." EFFOST Meeting Proceedings. Montpellier, France. Available at:

http://elsevier.conference-services.net/programme.asp?conferenceID=2939\&action=prog_presenters

Rubio-Rodríguez, N., Beltrán, S., Jaime, I., de Diego, S.M., Sanz, M.T., and Rovira Carballido J. 2010. "Production of Omega-3 Polyunsaturated Fatty Acid Concentrates: A Review." Innovative Food Science \& Emerging Technologies 11 (1): 1-12. doi:10.1016/j.ifset.2009.10.006.

Santana, P., Huda, N., and Yang, T.A. 2012. "Technology for Production of Surimi Powder and Potential of Applications." International Food Research Journal 19 (4): 1313-23.

Santibañez-Aguilar, J.E., González-Campos, J.B., Ponce-Ortega, J.M., Serna-González, M., and El-Halwagi, M.M. 2014. "Optimal planning and site selection for distributed multiproduct biorefineries involving economic, environmental and social objectives". Journal of Cleaner Production 65(15): 270-294.

Sendín, O.H., Vera, J., Torres, N.V., and Banga, J.R. 2006. "Model Based Optimization of Biochemical Systems Using Multiple Objectives: A Comparison of Several Solution Strategies." Mathematical and Computer Modelling of Dynamical Systems - MATH COMPUT MODEL DYNAM SYST 12 (5): 469-87. doi:10.1080/13873950600723442.

Shahidi, F. 2007. Maximizing the Value of Marine by-Products: An Overview. Series in Food Science Technology and Nutrition,. Woodhead Publishing.

Sigma-Aldrich. 2014. Novozymes:Quality Enviromentally-Friendly Enzymes-Analytical and Industrial Enzymes (Sigma-Aldrich). Price List.

Trincone, A.. 2011. "Marine Biocatalysts: Enzymatic Features and Applications." Marine Drugs 9 (4): 478-99. doi:10.3390/md9040478. 
Udenigwe, C.C., and Aluko R.E. 2012. "Food Protein-Derived Bioactive Peptides: Production, Processing, and Potential Health Benefits." Journal of Food Science 77 (1): R11-24. doi:10.1111/j.1750-3841.2011.02455.x.

U.S. EPA. 2005. Office of Transportation and Air Quality. Emission Facts - Average Carbon Dioxide Emissions Resulting from Gasoline and Diesel Fuel.

Vazquez, J.A., Rodriguez-Amado, I., Montemayor, M.I, Fraguas, J., Gonzalez. M.P., and Murado, M.A. 2013. "Chondroitin Sulfate, Hyaluronic Acid and Chitin/Chitosan Production Using Marine Waste Sources: Characteristics, Applications and EcoFriendly Processes: A Review." Marine Drugs 11 (3): 747-74. doi: $10.3390 / \mathrm{md} 11030747$.

Vidal-Giraud, B., and Chateau, D.. 2007. World Surimi Market. GLOBEFISH RESEARCH PROGRAMME. Food and Agriculture Organization of the United Nations, GLOBEFISH, Fish Products and Industry Division. http://www.globefish.org/upl/Publications/files/GRP\%2089.pdf.

Wackernagel, M., and Rees, W. 1996. Our Ecological Footprint: Reducing Human Impact on the Earth. New Society Publishers.

Weller, N. 2013. "BASF Looks to Biochemicals and Enzymes." Speciality Chemicals Magazine, June. Avaialble at: http://www.specchemonline.com/articles/view/basflooks-to-biochemicals-and-enzymes\#.VC1SAP1_uE4. 


\section{Figure captions:}

Fig. 1. Scheme of the pathways analysed for the valorisation of discards.

Fig. 2. General superstructure of the valorisation chain.

Fig. 3. Fish biomass. A) Optimal pathway configuration from an economic point of view. Plant working at maximum capacity is highlighted in red B) Optimal pathway configuration for $\boldsymbol{J}=\boldsymbol{J}_{\boldsymbol{e n}}$. D) C) Set of solutions with the best compromise between objectives. D) Optimal set of solutions if the waste treatment is considered. E) Typical set of pathway configuration with best compromise between objectives.

Fig. 4. Crustacean biomass. A) Optimal solution for $\boldsymbol{J}=\boldsymbol{J}_{\boldsymbol{e n}}$. B) Set of solution for the maximization of economic profit and minimization of environmental cost. C) Optimal pathway configuration from an economic point of view. D) Typical configuration of the set of solutions with best compromise between objectives. E) Alternative pathway where the not used parts could be incorporated to a crustacean meal line. F) Set of solutions to the modified pathway presented in A. G) Set of solutions where the environmental cost of the waste treatment is considered. H) Optimal pathways combination for the considered technologies.

Fig. 5. Cartilaginous biomass. A) Set of solutions for the considered valorisation processes. B) Best environmental solution, where no products are obtained. C) Optimal economical solution, where CS, enzymes and gelatine are obtained as products. D) Typical pathway configurations with better compromise between objectives. E) Set of solutions for the considered valorisation process if $\boldsymbol{J}_{\text {waste }}$ is considered. D) Typical pathway configurations with better compromise between objectives. 